\title{
Investigation into the use of learning agreements to enhance stakeholder engagement and promote self-efficacy in computing education.
}

BALLEW, W., MCDERMOTT, R., ZARB, M., DANIELS, M., CLEAR, T. 


\section{Investigation into the Use of Learning Agreements to Enhance Stakeholder Engagement and Promote Self- Efficacy in Computing Education}

\author{
William Ballew, Roger \\ McDermott, Mark Zarb \\ School of Computing Science and \\ Digital Media \\ Robert Gordon University \\ Aberdeen, United Kingdom \\ w.ballew@rgu.ac.uk \\ roger.mcdermott@rgu.ac.uk \\ m.zarb@rgu.ac.uk
}

\author{
Mats Daniels \\ Department of Information \\ Technology \\ Uppsala University \\ Uppsala, Sweden \\ mats.daniels@it.uu.se
}

\author{
Tony Clear \\ School of Computing and \\ Mathematical Sciences \\ AUT University \\ Auckland, New Zealand \\ tony.clear@aut.ac.nz
}

\begin{abstract}
We examine controversial issues surrounding the locus of control in the implementation of learning agreements, plans or contracts, in the context of the U.K. university-level Graduate Apprenticeship scheme. We begin by giving an account of the stakeholders and their positions as well as their motivating principles as they strive to maintain their respective loci of control with regard to the negotiation of the learning agreement. We then describe the idiomatic challenges to implementation of a learning agreement and subsequent plan in work-based learning environments with a range of employers from different sectors. An investigation into the manner in which learning agreement tenets are changed due to competing pressures on the various stakeholders leads to a discussion of challenges to successful prioritisation of the learning plan that occur as a result of mutually exclusive requirement sets. We discuss the challenges that may present themselves in which the requirements of one set of stakeholders appear to conflict with others and the questions that are raised as those involved seek to ensure suitable standards of academic quality in difficult cases. Finally, we discuss whether learning agreements are the most appropriate operational instruments for maintaining standards in these circumstances.
\end{abstract}

Keywords- learning agreement; learning plan; work-based learning; locus of control; stakeholder prioritisation; academic quality; academic integrity

\section{INTRODUCTION}

Learning Agreements, learning plans or learning contracts $[1,2]$ have been employed within a Higher Education setting for a number of years, where they have been used to enhance motivation and facilitate the self-directed learning of students [3]. This is done by promoting reflection on the roles of various parties within the educational process, clarifying the expectations and responsibilities that follow from those different roles, and enabling stakeholders, particularly the learner, to negotiate and set appropriate educational goals. It is claimed that the practice of prioritisation, reflection and negotiation, which is an integral part of the construction of these documents, provides students with the opportunity to take greater ownership of the learning process and so develop a greater commitment to achieving their educational objectives.

However, in the current political climate, we are seeing the rise of increasingly instrumental responses by Western neoliberal Governments [4] to perceived needs for graduates in areas of industrial shortfall. STEM disciplines and computing are especially vulnerable to such deliberate steering of the curriculum through performance indicators and narrowly targeted funding models developed by enthusiastic policy analysts and politicians [5]. While models of project- and problem-based learning, and curricula which suit graduates for the world of work, are not new, and while they resonate with the pragmatic Deweyan notions of preparing graduates for the world ahead of them, earlier models also had the broader goal of preparing students to be more broadly educated citizens able to participate in and contribute actively to democratic societies. The desire to shorten the path to producing productive Information Technology "professionals", as well as narrower "technicians", has led to innovative experiments in work-based learning. Boot camps and the graduate apprenticeship scheme in the United Kingdom are two such responses.

Even so, models of work-integrated learning (WIL) can bring severe tensions. Tertiary education is inherently a multistakeholder endeavour. For instance, in his discussion of quality education in engineering disciplines, Woollacott [6] identified four kinds of curriculum responsiveness associated with four principal stakeholders. The first is economic responsiveness, which deals with how the curriculum reacts to the demands for highly qualified workers who can engage in the tasks necessary 
for the smooth running of modern globalized economies. The second is disciplinary responsiveness, which is a function of how well the curriculum can adapt itself to ensure that students receive an education that is informed by the best scholarship and academic and professional practice. A third type of responsiveness is cultural or societal in nature and depends upon how easily the educational system can incorporate the cultural diversity of students, while the fourth is learner responsiveness, which reflects how the curriculum can accommodate the individual learning needs of students. The stake-holders in the first, second and third cases are the workforce, the discipline, and society as a whole. Only in the fourth case is the student the primary stakeholder, and consequently, only if we ignore the wider socioeconomic and academic consideration of higher education do we arrive at a concept of "student as customer". In critiquing educational quality assurance, Pears [7] likewise draws a distinction between the tensions in quality models: quality as delivery of the curriculum, quality as service to the "customer", and quality as development of the student.

While the definition of what counts as work-based learning may depend upon the particular situation, we take it to include the type of learning environment that is informed by professional practices, and we take as our starting point, the common characterisation of work-based learning used by Lester and Costley [8], namely, "any learning that is situated in the workplace or arises out of workplace concerns". Clear et al. [9] also describe a continuum of work-integrated learning scenarios, ranging from case studies in the classroom, through projectbased learning to forms of cooperative education. Pilgrim and colleagues [10] have also outlined a similar range of activities and educational strategies. Nevertheless, while drawing this boundary quite wide, there are still distinctions that can be made. We can, for example, distinguish between the original conception of work-based learning, e.g. [11], workplace learning [12], work-integrated learning [13], and work-related learning [14]. Each of these has a slightly different emphasis which is reflected in different implementational forms. However, an important point, especially in the context of the graduate apprenticeship scheme, is that some conceptions of work-based learning, especially those created early on in the development of the concept, were originally much more transformational. Boud [15], for example, envisaged a situation in which students would "undertake study for a degree or diploma primarily in their workplace and their learning opportunities [would] not [be] contrived for study purposes but arise from normal work." This form of work-based learning has rarely been implemented but it forms the fundamental vision and motivating idea behind the U.K. graduate apprenticeship scheme.

The role of learning agreements in models of project-based and cooperative education [16] has been seen as critical to process of balancing the goals of each stakeholder: the employer for work-related outcomes; the university for articulating what constitutes the operational structure of the academic programme and what the achievement of credible academic goals looks like; and the student for a clear statement of, and commitment to, a set of defined learning goals around which the work placement may be framed. An imbalance in any of these roles puts the whole notion of WIL at risk. Heavily steered, high-stakes funding models have the potential to upset this delicate balance by shifting the locus of control away from the balance point for achievement of academic goals and, in this event, would act to undermine educational quality. It is in the nature of stakeholders that each has some degree of legitimate interest but it is clearly improper for one to dominate at the expense of the others. From the employer side, this may be due to overriding commercial concerns which detract from their ability to create a suitable work-based learning environment; the student may lack sufficient commitment to the programme and seek to use other work-related issues to undermine the importance of the academic work and the university partner may become enamoured of innovative new delivery methods at the expense of proven teaching methods.

Recently, a new work-embedded academic programme has been proposed and implemented in Scotland, part of the United Kingdom. Known as the Graduate Apprenticeship (GA) scheme, it attempts to fully integrate university study within full-time employment, with the government's directive pushing for an $80 / 20 \%$ split in responsibility for delivery, that is, $80 \%$ of the student learning was to be done in the work-based learning environment (WBLE), and 20\% via university contact hours and self-directed study. Individuals are employed by companies or organisations which are required to create appropriate learning environments which allow students to carry out suitable learning tasks within their day-to-day work. Such a mode of study is qualitatively different from "day-release" or distance-learning models. Within this structure, learning agreements have been used to ensure that all stakeholders, in organisations with employees engaged in the scheme, understand the resource implications of participation and are able to provide appropriate opportunities for students to satisfy learning goals.

The situation in Scotland prior to September 2017 was such that students wishing to attain professional work experience while simultaneously being enrolled in university were limited to work-placement programmes in industry of up to one year in length, after which they returned to the traditional classroom environment in order to complete their degrees. In complete contrast, the Graduate Apprenticeship programme can offer fulltime university enrolment to the full-time employed apprentice. The GA brings with it a unique set of opportunities and challenges that must renew the call for more emphasis on flexible learning practices in Higher Education [17]. In addition, it will need new directions for pedagogy involving work-based learning environments that integrate employers into the actual learning agreement at levels of responsibility that present unique challenges to Higher Education, particularly with regard to roles and interests of stakeholders in the defined $80 / 20 \%$ delivery responsibility split.

There are many advantages to this: the traditional course offers its graduates a curriculum vitae typically containing four years of study plus an optional year of work experience via placement. The GA, on the other hand, appears to offer its honours graduates (fourth year of university studies in the Scottish system) a CV containing four years of work experience with four years of study.

While the advantages are evident, the process of reflection to learn lessons from the implementation of the GA programme has 
uncovered challenges to conventional pedagogical and a range of philosophical questions surrounding the development of learning plans within an educational environment that relies heavily on an employing organisation for delivery of practical learning in the WBLE. The fundamental challenges for each stakeholder can be summarised as follows. The university partner needs to find an appropriate way in which to maintain academic rigour in the programme while necessarily ceding a significant amount of control for the learning environment to the employer. The employer is required to engage in an appropriate way with the creation and maintenance of a complex and dynamic learning environment, even when there is no immediate return on this investment and resource allocation. The student is required to engage with the learning environment both in an academic and an employment context and devote appropriate resources to each facet of their role. The main stakeholder vehicle for detailing the engagement with this issue is the learning agreement. Nevertheless, challenges arise from dealing with limitations in the implementation of such agreements designed to promote stakeholder engagement with the GA programme while simultaneously promoting self-efficacy in computing education.

In order to examine this issue, we make use of the concept of a "Locus of Control" [18]. This is a psychological construct originally developed in the context of Personality Trait Theory and extended to areas such as motivational theory, e.g. by Ajzen in the Theory of Planned Behaviour [19]. The locus of control is degree to which people believe that they have control over the outcome of events in their lives, as opposed to external forces beyond their control. In this paper, we use the term to refer to the belief by the stakeholder that they are able to have control over the learning process, possibly but not necessarily within the context of the learning agreement.

In this paper, we examine the use of learning agreements/learning contracts and the corresponding learning plan suitable for the educational situations described above. We understand the agreement or contract to indicate a collaboration agreement of participation between the university and the employer with reference to a particular student. The learning plan is then understood as the expression or realisation of that obligation between the mentor and student vis-a-vis the university's learning outcomes. We begin by giving an account of the historical development of these documents as well as their motivating principles, and then describe their deployment as part of the wider pedagogical process. Although both the circumstances and operational purposes may differ, we find that there is some degree of commonality in approach and outcome which suggests that such documents may find practical application in a wider range of computing and engineering contexts. However, from this work, it appears that much greater thought would be needed to ensure that the learning agreements draw engagement from all stakeholders.

\section{ENHANCING STAKEHOLDER ENGAGEMENT: LOCUS OF CONTROL CHALLENGES}

While we have previously illustrated the different stakeholders with regard to university, student and employer, in the case of the Graduate Apprenticeships, it is useful to admit a subcase of the employer organisation, namely the workplace mentor of the student and we will henceforth talk about four stakeholders involved: the employing organisation, the mentor, the student/apprentice, and the university. Within two of those components - namely the employing organisation and the university - there are additional, secondary stakeholders that can apply pressure to the learning agreement in either conflicting or collaborative ways. Examples of secondary stakeholders might include the student/apprentice's organisational line manager (who may not necessarily be the mentor) or the university's business development function, which may have the added pressure of recruitment targets to meet, and thus may have competing motivations for signing organisations onto the programme. Each stakeholder comes with its own array of interests (i.e. its own concept of social or economic locus of control), and there may therefore be complex, dynamic matrices of competing tensions and pressures between both internal and external entities within the employing organisation as well as the university. These separate agendas and requirements can lead to distortion and displacement of the actual goal: the provision of a successful degree programme for student/apprentices. In other words, there is the potential to lose sight of the one thing that all the stakeholders had initially agreed upon when they started out on this journey together because they have different conceptions of the journey itself.

Stakeholders typically adds complexity to a given situation and, as discussed in Ramirez [20], there can be as many as nine identifiable contextual facets that come into play when attempting to accommodate the array of interests represented by stakeholders. These facets include aspects such as the nature of the problem, the stakeholders themselves, the convenor, the networks, stakeholders' capacities, and stakeholders' choices in dealing with conflict and negotiation, etc. Within these aspects, and using football as a metaphor, we can delineate specifics regarding the players and their relative positions on the playing field with regard to the particular problem set to be addressed in negotiations, i.e. where the ball is moving to and from at any given moment and where the goals are statically located.

Likewise, it is unsurprising that stakeholder perceptions vary based on individual perspectives and positions [17], however, this is where the football metaphor reaches its limits: the players must accept that it is potentially unproductive to engage in a learning agreement negotiation as if it were a game in which the scoring of goals at the expense of the other team necessarily means that fifty percent of the players on the field walk away winners and fifty percent losers. Rather both teams must ideally work toward manoeuvring the ball toward a single goal for the benefit of the student/apprentice. It is precisely not falling into this sort of contentious dynamic that is part of the pedagogical and philosophical challenge, particularly when the teams in question are founded on wholly divergent philosophical underpinnings, e.g. optimising commercial profit margins vs. academic programme delivery.

This divergence of basic mission necessarily affects the starting positions in learning agreement and learning plan negotiations and will, if not checked, detrimentally affect the outcome by distorting expectations on both sides, leading to struggles over locus of control. Businesses remain in business because of profits - public sector organisations are run differently but are still held to audit-mandated cost controls and 
efficiencies. Thus far, our experience with the GA suggests that it is possible that primary stakeholders may be negotiating from antithetical viewpoints, yet are potentially unaware that they are doing so, causing distortions in expectations that have the potential to impact directly on successful expression of the learning agreement in the learning plan.

One example of this has arisen in the GA Programme taught by the School of Computing Science and Digital Media at the Robert Gordon University (RGU), in Aberdeen, Scotland. An informal, free-response survey was administered to both mentors and student/apprentices during their respective induction events that queried demographic information in addition to posing questions designed to elicit information regarding personal motivation for participation in the GA. Freeresponse student/apprentice questions included:

- What are your main aims in undertaking this apprenticeship degree?

- What skills are you most keen to develop within this apprenticeship degree?

- Why did you choose to study via the GA? What were your considerations?

- Does your organisation seem well resourced to support apprentices?

- What do you think will be the main challenges for you and/or your family (if applicable)?

- Why did you choose this apprenticeship rather than a full-time degree?

Preliminary tabulation of survey results on the free-response portion suggests that responses from 29 student/apprentices and 15 mentors to questions regarding skills development expectations were answered very differently by both parties. The majority $(60 \%)$ of mentors reported expecting that their student/apprentices would gain 'professional and managerial skills', whereas half of student/apprentices (overwhelmingly the mode accounting for $50 \%$ of all respondents) expressed the expectation of gaining 'additional technical skills' via the programme. This divergence of basic outcome expectation, if never dealt with as part of the mentor and student/apprentice negotiation of the learning plan, could easily lead to later struggles and dissatisfaction with the programme based on skewed perceptions of success or failure in goal achievement.

In negotiations of the learning agreement among any or all stakeholders, the degree of distortion (both positive and negative) that can be inflicted by competing pressures and tensions is likewise proportionate to the degree of flexibility built into the learning agreement and the perceived division of gains derived from it [21]. From a psychological standpoint, intuition tells us that the more flexible the learning agreement, the happier everyone will be with its implementation, and even though we know this can introduce all sorts of vagueness into the process, we continue to believe it as if it were simply common sense. After all, flexibility is accommodating, and how could that result in very much conflict?

From the employer's side, pressures on the learning agreement include normal, operational, business-driven requirements that keep the organisation up and running, such as profits, efficiencies, production rates, etc. From the university's perspective, workload planning, submission deadlines, administrative requirements, and grading criteria play an important role in how the learning agreement is fulfilled and how the underlying tenets of academic quality and integrity are met. Finally, from the employee/apprentice's perspective, maintaining a work/life/study balance is likely a primary goal, especially for those whose need to maintain employment in order to support families.

For example, a learning agreement might have a requirement of freeing up time during the working-week for the employee/apprentice to participate in university-related events such as online lectures or discussion tutorials. This principle may be acceptable to the employer at first, at least until seasonal requirements, such as fiscal year-end audits, and budget reconciliations demand more of the employee/apprentice's time, at which point the agreement may suddenly come under pressure and the requirement become distorted or, in some cases, be disregarded in favour of the immediate needs of the employer. If the university is not a particularly commercially minded entity, it may fail to fully grasp the significance of this change in workplace requirements, and thus may not know how to appropriately respond - or may not have the flexibility to do so once the content and assessments have been set. Meanwhile, the employee/apprentice may suffer under an ever-increasing workload, caught between a less-than-subtle shift in dynamic that has suddenly created opposing teams fighting hard to reach opposite goals, both echoing each other's cries of 'but we can't ...', while generating competing loci of control.

Within the context of the GA, issues of loci of control are particularly striking and may lead to unexpected challenges to the learning agreement, hampering negotiation efforts for all stakeholders. At its foundation, the most challenging aspect of the locus of control discussion finds its root in one unique problem set: in no other endeavour does the university, as a primary stakeholder, cede the majority portion of responsibility for delivery of academic content to an external entity over which it has no control. Stated succinctly, the employing organisation has an almost 2:1 burden of responsibility (160 hours vs. 90 hours per module respectively) to generate and maintain a learning environment for the apprentice where it is tasked with successful delivery of a given module's contents. In the case of the RGU graduate apprenticeship scheme, with an inaugural student/apprentice cohort of 27 students with 19 separate work sites, this problem set presents formidable philosophical, pedagogical, and real-world resource challenges to longstanding concepts such as academic quality and integrity as well as oversight and monitoring.

The research literature tells us that once the learning agreement becomes distorted to meet the needs of one side or the other, uncertainty over the applicability of the agreement sets in for both sides regarding expectations of distributional cooperation. According to Koremenos [22], this may, simultaneously, potentially increasing the remaining latitude for additional distortion. However, unlike in that case, the experience of the RGU programme is that there may be little possibility for renegotiation of the learning agreement once it is in place. This is in part because the learning agreement would 
then have to be renegotiated across all GA employers simply to address the needs of one, and in part because doing so would likely constitute an unwarranted drain on time and resources for the university. There may be an opportunity to address issues in one renegotiation session with all parties present, depending on cost, time, and resource, but this is unlikely to happen on a frequent basis.

This restriction on renegotiation may raise the "noise floor" within the framework by allowing additional possible variations of outcomes not related to the original learning agreement. For example, the employer may no longer allow the employee/apprentice to participate in the GA-related events that occur during the workweek due to the increased needs of the employing organisation and may use to its advantage the university's inability to enforce the tenets of the learning agreement effectively. This sort of constant testing of the power relationship within the stakeholder network reduces the student/apprentice from being a primary stakeholder, as we see in Woollacott's concept of the "student as customer", to being at best caught in the middle of a control struggle seeking to rearrange the demands of the student/apprentice's priority queue.

The reality, in many instances of learning agreement implementation, it could be argued that the employing organisation actually holds the upper hand in the relationship, and therefore may feel it can begin to dictate to the university certain aspects of delivery such as assessment submission deadlines or assignment workload levels for their student/apprentices. In such cases, the university as a stakeholder would have little recourse when employers fail to uphold their obligations as set out in the learning agreement or begin to distort it in their favour. The nature of the universityemployer relationship is such that the impact of non-fulfilment directly negatively falls predominantly on the university either in terms of the student/apprentice's performance or their potential threat of withdrawal from the programme. This may well be problematic in a situation where the programme is government-subsidised. Funding for student tuition is paid 'per head' by the government body supporting higher education apprenticeships, and so loss of students equates to loss of funding. This can quickly become a pressure point for maintaining the programme if student attrition rates are too high.

In many cases, the clauses laid out in the learning agreement may be less than binding and so lack any sort of appropriate enforcement procedure, punitive or otherwise, for nonfulfilment. Either disenrolling the student/apprentice or the ejecting the employer from the programme serves only to punish the student/apprentice, (and to the extent mentioned above, the university), not the employer, as it simply frees up more of the student/apprentice's time for extra-GA commercial work, thereby meeting the employer's needs while preventing the student/apprentice from reaching the goal of obtaining a degree.

Alternatively, if in the judgement of the employer, demands levied by the university were to become too great, there is a possibility that the student/apprentice's employment may be terminated in order to circumvent the problem. This point is related to an obvious question that primary stakeholders would need to answer namely "When does this person become useful to the company?" The viewpoint that the student/apprentice needs to have an implied 'immediate usefulness clause' built into the agreement may further serve to undervalue the student/apprentice to the organisation, again implying expendability until such a time as the student/apprentice becomes 'useful' as judged by the employer. Should termination ensue, the student/apprentice would have to leave the programme, since employment is a required pre-condition for an apprenticeship.

In the current GA relationship complex, the employer ultimately holds the upper hand: any attempt on the part of the university to undertake measures viewed as punitive by an employer in order to make binding a learning agreement would likely result in the discontinuance of the employer's relationship with the university. Such termination of relations, depending on the programme's funding source (e.g. government subsidy per head) and/or any potential future student/apprentice pipeline that employer represents, would certainly harm the university more than the employer in the long-term and would certainly prove most harmful to the student/apprentice(s) that employer might represent.

Nevertheless, there is still some negative impact for the employer if such a course of events were to take place. Part of this is poor public relations which the organisation may or may not be in a position to manage. Such a human resource narrative may not be beneficial to the business, negatively impacting relationships with potential customers, other employees, the university and government agencies. Therefore, within the context of multiple employer-university relationships, it is most beneficial for all parties to come to - and stick to - a learning agreement that is amenable to all stakeholders up front, making only minor incremental changes along the way as learning increases.

\section{SELF-EFFICACY AND THE LEARNING AGREEMENT: FACILITATING A GOOD WORK-BASED LEARNING ENVIRONMENT IN THE ABSENCE OF CONTROL}

It is interesting to investigate this problem through the lens of Bandura's Social Cognitive Theory [24], specifically his concept of self-efficacy, that is, "belief in one's capabilities to organise and execute the courses of action required to manage prospective situations" [25]. This concept can be applied to the lecturer as facilitator, the student/apprentice, and the mentor in potentially different ways. For example, in an ideal situation, the lecturer is hopefully looking for effective ways to facilitate the delivery of the course materials that involve the employer and the student/apprentice in a synergistic fashion. Doing so successfully would create a sort of 'facilitated buzz' of engagement in and around the learning objectives, rather than lecturing in the old 'sage on a stage' role, merely presenting the information and hoping for its transformation into wisdom and practical application to magically occur in the WBLE. The student/apprentice, again in the ideal, is actively seeking out opportunities to engage the material and apply it to the WBLE in proactive ways, taking presented theory and exercising it in practical application in order to accomplish relevant tasks designed to meet learning outcomes in the WBLE. The ideal mentor is looking for opportunities to provide the student/apprentice with the needed platform for this practical 
application, potentially rotating the student/apprentice through a number of projects and/or departments within the WBLE where that applied learning can take place (e.g. spending time directlearning in the finance department during the finance and accounting module). In this case, the operation runs smoothly, and each part can count on the other to do its job effectively.

The reality, in many cases, is very different. Locus of control issues may begin to creep into the picture early in the recruitment process, particularly in terms of differing priorities among the three parties mentioned above. Attempts to manage expectations may also become increasingly challenging over time, within the ebb and flow of the employers' requirements and their impact on the student/apprentices. Cognitive biases can easily begin to lead each party to the conclusion that their immediate - and often short-term - priorities can overshadow the long-term GA's priorities as expressed in the learning agreement. This may mean that the learning agreement eventually becomes superfluous. This combination of skewed priorities and confirmation biases may place a severe strain on both the commercial organisation's sense of self-efficacy as well as that of the university. If both sides quickly come to the conclusion that they cannot be successful or effective until and unless their mutually exclusive priorities are met, then collaboration between stakeholders will break down. If organisations, particularly in the private sector, will always prioritize their requirements first then the university's and GA's requirements will always be secondary. This should be of little surprise given the current shareholder model which operates in most markets.

From the business perspective, anything that might detract from, or interfere with, the business's ability to generate value for its clients and return profits is viewed as a potential drain on, or threat to, the existence of the company. Some companies, upon learning more about the level of responsibility for delivery placed on the WBLE, may therefore opt out of the GA. It is interesting to note that the RGU survey also revealed some disparity between responses of mentors and student/apprentices when questioned about whether their respective organisations could provide adequate support: student/apprentices answered overwhelmingly in the affirmative $(0 \%$ answered negatively with only three students answering 'don't-know' out of 26), while the majority of mentors expressed concerns over the ability of the organisation to provide appropriate support (60\% answered in the 'low-to-challenged' range). These results suggest that the mentors' elevated positions within their organisations could have provided them with special insight into strategic cost-benefit concerns that were not available to the student/apprentices.

Interpersonally, and following the same organisational logic, it is also possible that line managers and mentors who do not themselves possess a university degree may not place high value on an apprentice's attainment of a degree. Indeed, the successful student/apprentice may even be viewed as a future threat to the manager's position. Issues about locus of control would clearly be present here and may often be manifested in unexpected ways that have deleterious effects on perceptions of self-efficacy for both sides, particularly since the university has limited purview of, recourse against, or ability to incentivise employers' various behaviours. The university can only seek to influence through recommendation on an employer's selection of mentors and student/apprentices and the governing processes that are assumed to operate in the background. Guidelines and recommendations can be set and agreed upon by both parties, but if they are not followed, the university ultimately has limited recourse other than cancelling the agreement. It should also be noted that even when an employer, in good faith, wants to comply with programme requirements, there may be times when business needs may exceed agreed-upon aspects of the learning agreement to the detriment of the student/apprentice.

Even if the university were able to achieve some measure of influence or control over each employer's apprenticeship process, it may be that long-term oversight and monitoring would come at such a cost to the university in terms of time and resources that it would become infeasible to maintain it across large numbers of worksites and all student cohorts at all stages of the degree programme. Moreover, any attempt to inject heavy monitoring and oversight into a given business's processes could be viewed as overly invasive by the employer and lead to other negative relationship repercussions in the long term. Finally, the question of mission validity is also cogent. Is controlling business processes for external partners even a valid remit for a university attempting to run a GA programme? These sorts of control issues require significant consideration if the programme is not to fail at an early stage.

\section{CONCLUSIONS}

Finding solutions for issues such as those discussed above hinges on the development of a learning agreement that impels the employer to want to do the right thing while meeting requirements that are not necessarily directly, immediately beneficial to the business. In other words, in an ideal world, the learning agreement should be negotiated in such a way that the employer finds fulfilment of the tenets of the agreement from within the WBLE acceptable in a way that does not damage the business. Furthermore, it should do this in terms of learning quality and volume, as well as academic integrity to a level that is also acceptable to the university and the accrediting body (or bodies) relevant to that degree programme. The learning agreement requirements must also be achievable in a costefficient manner with minimal oversight by the university but with maximum compliance to the agreement. Furthermore, the programme also has to be achievable by the student/apprentice within a four-year timeframe in such a way as to mitigate attrition by not significantly diminishing their quality of life. With these ideas in mind, the learning agreement must not only be drafted properly, but must also strive for hard-won buy-in from all stakeholders: they must want to do it, not feel that they're being coerced into doing it against their will or better judgement. The ability of stakeholders, especially employers, to enter into the level of compromise required to get such an agreement in place poses important, serious questions about where compromise occurs and what its consequences might be.

With regard to GAs, there is a danger that the most likely area for compromise is around academic quality and integrity, simply because the motivational factors involved in the decision-making process will necessarily prioritise the monetary gains offered to the programme through enrolment retention above maintaining delivery at a level required to meet the 
academic quality and integrity standards as expressed by the accrediting body as well as the university administration. In the current shareholder model environment that is operating both in academia and industry [24], there is a danger that financial gain will be prioritised above ethical and pedagogical considerations, and that compromises will be made to accommodate the difficulties associated with this new and challenging delivery method.

The use of Learning Agreements to capture stakeholder responsibilities, in a form that can be used to foster trust and commitment by all parties in the programme, is a hard problem. Nevertheless, we believe that articulation of the major issues that give rise to this problem is a necessary first step in finding a resolution to the issues of lack of monitoring and oversight without potentially compromising academic integrity. We have not yet found sufficiently appropriate wording for a collaboration and learning agreement that resolves the costtime-resource tensions between stakeholders while delivering a degree programme in a WBLE based on high academic standards. However, we believe that we have made progress in detailing the questions that such a solution would address in this exploratory paper. Given significant public investment and the direction of substantial educational resources to setting up the Scottish graduate apprenticeship scheme, the issues raised here will continue to exercise academics and be explored by universities, industry and government. We believe that further research in this area is warranted and hope to present the results of such investigation and analysis in subsequent work.

\section{REFERENCES}

[1] Garnett, J. 2000. Organisational cultures and the role of learning agreements. In Work-based learning and the university: New perspectives and practices (SEDA Paper 109), ed. D. Portwood, and C. Costley. Birmingham: Staff and Educational Development Association

[2] Gibbs, P. 2009. Learning agreements and work-based HE, Research in Post Compulsory Education, (14),1, 31-41.

[3] Chyung, S.-Y., 2007. Invisible motivation of online adult learners during contract learning. The Journal of Educators Online, 4(1).

[4] Clear, T., 2016. Thinking Issues: Evaluating research impact in computing: A slippery slope?. ACM Inroads. 7, 4, pp. 28-32.

[5] Clear, A., and Clear, T., 2014. Introductory Programming and Educational Performance Indicators - a Mismatch. In Lopez, M., and Verhaart, M. (Eds.) Proceedings of ITx New Zealand's Conference of IT. Citrenz, pp. 123-128

[6] Woollacott, L.C., 2009. Taxonomies of Engineering Competencies and Quality Assurance in Engineering Education. Engineering Education Quality Assurance, pp 257-295.

[7] Pears, A. N., 2010. Does quality assurance enhance the quality of computing education?. In Proceedings of the Twelfth Australasian Conference on Computing Education. Tony Clear and John Hamer
(Eds.), Vol. 103. Australian Computer Society, Inc., Darlinghurst, Australia, pp. 9-14.

[8] Lester, S. and Costley, C., 2010. Work-based learning at higher education level: value, practice and critique. Studies in Higher Education 34 (5)

[9] Clear, T., Claxton, G., Thompson, S., and Fincher, S., 2011. Cooperative and Work-Integrated Education in Information Technology. In Coll, R., and Zegwaard, K. (Eds.) International Handbook for Cooperative \& Work-Integrated Education. World Association for Cooperative Education Inc., 2 ed., pp. 141-150.

[10] Pilgrim, C. J., \& Koppi, T., 2012. Work integrated learning rationale and practices in Australian information and communications technology degrees. In Proceedings of the Fourteenth Australasian Computing Education Conference. Vol. 123. Australian Computer Society, Inc., pp. 25-32.

[11] Raelin J.A., 2000 Work-Based Learning. Prentice-Hall, Upper Saddle River, NJ.

[12] Billett, S., 2001. Learning in the workplace: strategies for effective practice (Sydney, Allen \& Unwin).

[13] Jackson, N., 2006. Work-integrated learning in the UK: an overview. University of Surrey: Surrey Centre for Excellence in Professional Training and Education.

[14] Maurer, T. J., Weiss, E. W., \& Barbeite, F. G., 2003. A model of involvement in work-related learning and development activity: The effects of individual, situational, motivational, and age variables. Journal of Applied Psychology, 88(4): 707-724.

[15] Boud, D., 1995. Assessment and learning: contradictory or complementary. In P. Knight (Ed.) Assessment for learning in higher education, pp.35-48, London: Kogan.

[16] Clear, T., McDermott, R., Parsjö, E., Cajander, Å., Daniels, M., \& Lagerqvist, N., 2016. A framework for writing learning agreements. In Frontiers in Education Conference (FIE), 2016 IEEE, pp. 1-8.

[17] Guskey, T. R. (2007). Multiple Sources of Evidence: An Analysis of Stakeholders' Perceptions of Various Indicators of Student Learning. Educational Measurement: Issues and Practice, 26, pp. 19-27. doi:10.1111/j.1745-3992.2007.00085.

[18] Lefcourt, H. M., 1991. Locus of control. In J. P. Robinson, P. R. Shaver, \& L. S. Wrightsman (Eds.), Measures of social psychological attitudes, Vol. 1. Measures of personality and social psychological attitudes (pp. 413-499). San Diego, CA, US: Academic Press.

[19] Ajzen, I., 2002. Perceived behavioral control, self-efficacy, locus of control, and the theory of planned behavior. Journal of Applied Social Psychology, 32, 665-683.

[20] Ramirez, M., 2002. Innovation in Production and the Restructuring of Work Organisation and Employment in the Telecommunications Service Sector, Vol. PhD, Manchester: UMIST.

[21] Koremenos, B., 2001. Loosening the Ties that Bind: A Learning Model of Agreement Flexibility, International Organization. Cambridge University Press, 55(2), pp. 289-325. doi: 10.1162/00208180151140586

[22] Bandura, A., 1977. Social cognitive theory. Englewood Cliffs, NJ: Prentice Hall.

[23] Bandura, A., 1997. Self-efficacy: The exercise of control. New York, NY: Freeman

[24] Allaire, Y. (2014). What is the Role of Business? World Economic Forum, https://www.weforum.org/agenda/2014/01/role-business/ accessed 1 May 2018. 